\title{
Trace elements in nature water of the Naryksko- Ostashkinskaya area (Kuzbass, Russia)
}

\author{
Olesya Lepokurova ${ }^{1,2, *}$, and Eugenia Domrocheva ${ }^{1}$ \\ ${ }^{1}$ Tomsk Branch of Trofimuk Institute of Petroleum-Gas Geology and Geophysics of SB RAS, 4, \\ Academichesky ave., Tomsk 634055, Russia \\ ${ }^{2}$ National Research Tomsk Polytechnic University, Lenin Avenue, 30, Tomsk 634050, Russia
}

\begin{abstract}
This paper presents data on the trace element composition of lake waters, river waters and groundwater in the area of coalbed methane production. The concentration dependences of some components on the mineralization, organic matter and depth are revealed. It is shown that underground waters of coal deposits are most enriched in microelements.
\end{abstract}

\section{Introduction}

Despite the insignificant amount of microcomponents in water, they are of great importance for environmental and exploratory research. One of these tasks was set by IPGG SB RAS staff collaborating with LLC Gazprom Dobycha Kuznetsk on hydrogeology, hydrogeochemistry and ecology of potential industrial production areas of coal bed methane in Kuzbass. Recent studies have focused on the NarykskoOstashkinskaya area in the Erunakovsky district of the Kemerovo region, being the most promising for coal bed methane production. This paper presents the results from one of the study stages, i.e. the investigation of the microcomponent composition properties of the surface and ground waters in this area.

\section{Research object and methods}

The area under consideration is located in the central part of the Kuznetsk coal basin (Fig. 1). In the geological structure of the area there are coal-bearing sediments of the Yerunakovskaya subseries of Upper Permian age, Triassic, Jurassic, and Quaternary sediments. Hydrogeological conditions and chemical analysis of groundwater have been presented in detail $[1,2]$. In the study area a straight vertical hydrodynamic zonality can be distinguished, according to which, two zones are identified due to the intensity of water exchange occur: active and slow water exchange. The waters of both zones differ in chemical and gas composition and follow direct vertical hydrogeochemical zonality.

The microcomponent composition of water was determined by the mass spectral method with inductively coupled plasma (ICP - MS) in IGM SB RAS (Novosibirsk). In

\footnotetext{
* Corresponding author: LepokurovaOY@ipgg.sbras.ru
} 
total, 43 samples were selected: four lake samples, 10 river samples and 29 groundwater samples. The study results are presented in Table 1.

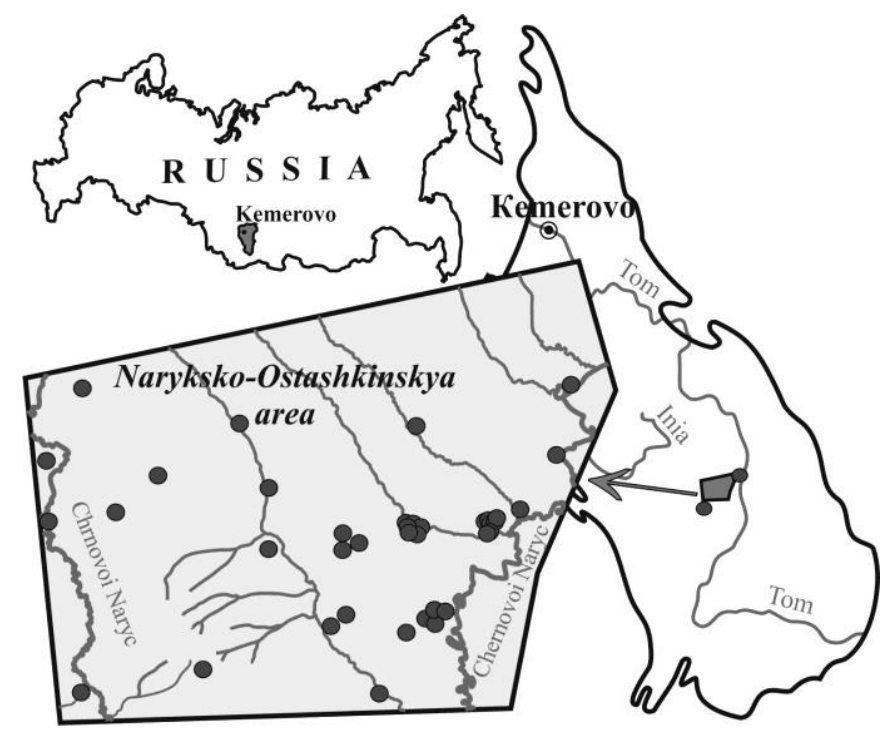

Fig. 1. Scheme of location of sampling points of natural waters.

\section{Experimental data}

Lake water and water of sediment ponds. This water is fresh (salinity $0.1-0.8 \mathrm{~g} / \mathrm{L}$ ) and

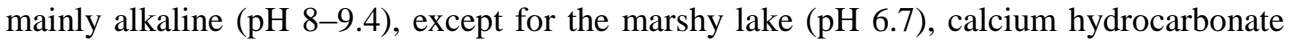
water and calcium hydrocarbonate-sulfate water in one pond. The water is characterised by a relatively low content of microcomponents. Only $U$ differs from the rest of the waters, the content of which varies from $0.8-4.1 \mu \mathrm{g} / \mathrm{L}$, with an average of $2.6 \mu \mathrm{g} / \mathrm{L}$, which is twice as high as its concentration in the hypergenesis zone and two orders of magnitude more than in the river. However, its maximum concentrations were found in the ground water of short residence time.

River water. Within the study area water samples were collected from the rivers, such as Chernova Naryk (the main water way), Kazanchushka, Daryina Rechka, Berezovaya, Bolshaya Rechka, Osinovka and an unnamed stream. There is fresh water (salinity 0.3-0.6 $\mathrm{g} / \mathrm{L}$ ), weakly alkaline and alkaline water ( $\mathrm{pH}$ from 7.6-8.9) and calcium hydrocarbonate water with a sufficiently high content of organic substances (DOC from 2.4-36.6 mg/L). The composition of the microcomponent was found to be chemically poorest from the presented natural water. Only Ni and Y were detected with concentrations of $0.5-1.7 \mathrm{mg} / \mathrm{L}$ and $0.002-0.055 \mathrm{mg} / \mathrm{L}$ (in four samples), respectively, and in other waters they were below the measurement limits.

Groundwater zones of short residence time are common in the upper part of the section formed by soft Meso-Cenozoic (mostly Quaternary) sediments and in the zone of intense jointing of Jurassic sediments. This water is fresh (salinity from $0.4-0.8 \mathrm{~g} / \mathrm{L}$ ) at a depth of approximately $150 \mathrm{~m}$. The chemical composition of water is calcium hydrocarbonate with mostly neutral, rarely weakly alkaline ( $\mathrm{pH}$ does not exceed 8). Everywhere content of microcomponents is more than for surface water. However, there are elements with concentrations even greater than in the lower aquifer. 
Table 1. Trace elements in nature water (allowable concentration and average value).

\begin{tabular}{|c|c|c|c|c|c|c|}
\hline \multirow{2}{*}{\multicolumn{2}{|c|}{ Parameters }} & \multicolumn{2}{|c|}{ Surface waters } & \multicolumn{3}{|c|}{ Ground waters with different residence time } \\
\hline & & Lake & River & Short & Long & Longer \\
\hline Salinity & $\begin{array}{c}\mathrm{mg} / \\
\mathrm{L}\end{array}$ & $\frac{0,1-0,8}{0,5}$ & $\frac{0,3-0,7}{0,4}$ & $\frac{0,4-0,8}{0,5}$ & $\frac{0,9-1,5}{1,2}$ & $\frac{10,0-19,6}{14,7}$ \\
\hline $\mathrm{pH}$ & - & $\frac{6,7-9,4}{8}$ & $\frac{7,6-8,9}{8,2}$ & $\frac{7-7,9}{7,6}$ & $\frac{7,5-9,9}{8,6}$ & $\frac{7,8-8,5}{8,2}$ \\
\hline \multicolumn{2}{|c|}{ Typ of water } & \multicolumn{3}{|c|}{$\mathrm{HCO}_{3}-\mathrm{Ca}$} & \multicolumn{2}{|c|}{$\mathrm{HCO}_{3}-\mathrm{Na}$} \\
\hline DOC & \multirow{7}{*}{$\begin{array}{l}\mathrm{mg} / \\
\mathrm{L}\end{array}$} & $\frac{4,1-15,3}{8,3}$ & $\frac{2,4-36,6}{9,6}$ & $\frac{1,3-7,9}{3,6}$ & $\frac{3,6-7,4}{5,2}$ & $\frac{12,8-52,8}{26,0}$ \\
\hline $\mathrm{Br}$ & & $\frac{<0,01-0,06}{0,03}$ & $\frac{0,01-0,07}{0,02}$ & $\frac{0,01-0,14}{0,06}$ & $\frac{0,16-0,32}{0,24}$ & $\frac{1,0-8,7}{2,89}$ \\
\hline $\mathrm{Sr}$ & & $\frac{0,08-0,60}{0,31}$ & $\frac{0,19-0,40}{0,27}$ & $\frac{0,05-0,99}{0,31}$ & $\frac{0,12-2,50}{1,31}$ & $\frac{1,0-6,2}{2,75}$ \\
\hline $\mathrm{Li}$ & & $\frac{0,0003-0,038}{0,019}$ & $\frac{0,002-0,120}{0,017}$ & $\frac{<0,01-0,08}{0,24}$ & $\frac{0,06-0,15}{0,10}$ & $\frac{1,0-7,0}{3,1}$ \\
\hline $\mathrm{Ba}$ & & $\frac{0,001-0,100}{0,041}$ & $\frac{0,004-0,120}{0,049}$ & $\frac{0,001-0,700}{0,131}$ & $\frac{0,41-0,26}{0,35}$ & $\frac{5,0-17,0}{12,0}$ \\
\hline B & & $\frac{0,04-0,06}{0,05}$ & $\frac{0,01-0,15}{0,03}$ & $\frac{0,03-0,29}{0,18}$ & $\frac{0,26-0,71}{0,49}$ & $\frac{0,3-16,0}{8,8}$ \\
\hline $\mathrm{Al}$ & & $\frac{0,004-0,150}{0,070}$ & $\frac{0,001-0,002}{0,001}$ & $\frac{0,0004-2,40}{0,53}$ & $\frac{<0,0001-}{\underline{0,02}}$ & $\frac{<0,01-1,0}{0,24}$ \\
\hline $\mathrm{Mn}$ & \multirow{15}{*}{$\mathrm{m} \mu / 1$} & $\frac{0,3-16,0}{9,8}$ & $\frac{<0,1-10,0}{0,4}$ & $\frac{0,5-400,0}{88,7}$ & $\frac{4,0-16,0}{10,0}$ & $\frac{<0,1-150}{35,4}$ \\
\hline I & & $\frac{9-36}{23,8}$ & $\frac{1,4-23,0}{5,9}$ & $\frac{<0,1-34,0}{20,0}$ & $\frac{56,0-69,0}{62,5}$ & $\frac{98,0-460,0}{228,5}$ \\
\hline $\mathrm{Sc}$ & & $\frac{0,25-2,4}{1,36}$ & $\frac{0,18-1,10}{0,33}$ & $\frac{0,04-40,0}{6,08}$ & $\frac{0,17-2,90}{1,54}$ & $\frac{0,27-4,1}{2,34}$ \\
\hline $\mathrm{V}$ & & $\frac{2,1-4,9}{3,5}$ & $\frac{0,8-5,6}{2,1}$ & $\frac{0,3-9,7}{4,2}$ & $\frac{1,5-27,1}{14,2}$ & $\frac{1,6-7,8}{4,7}$ \\
\hline Co & & $\frac{<0,01-0,22}{0,11}$ & $\frac{<0,01-0,63}{0,13}$ & $\frac{<0,01-13,0}{0,11}$ & $\frac{<0,01-0,71}{0,71}$ & $\frac{0,43-5,50}{2,11}$ \\
\hline $\mathrm{Ga}$ & & $\frac{0,4-4,9}{2,6}$ & $\frac{0,2-8,6}{2,7}$ & $\frac{0,3-46,0}{8,7}$ & $\frac{15,0-22,0}{18,5}$ & $\frac{250-1000}{714}$ \\
\hline $\mathrm{Ge}$ & & $\frac{<0,01-0,64}{0,46}$ & $\frac{<0,01-0,92}{0,05}$ & $\frac{<0,01-2,6}{0,72}$ & $\frac{0,71-1,5}{1,11}$ & $\frac{1,1-70,0}{27,56}$ \\
\hline Cs & & $\frac{\leq 0,1-2,4}{1,7}$ & $\frac{<0,1-1,1}{0,1}$ & $\frac{<0,01-40,0}{6,1}$ & $\frac{\leq 0,01-0,2}{0,5}$ & $\frac{0,3-4,1}{2,5}$ \\
\hline $\mathrm{La}$ & & $\frac{\leq 0,1-10,0}{3,33}$ & $\frac{<0,01-0,05}{0,03}$ & $\frac{<0,01-60,0}{10,53}$ & $\frac{\leq 0,01-1,2}{0,6}$ & $\frac{<0,1-30}{5}$ \\
\hline $\mathrm{Pb}$ & & $\frac{<0,1-4,6}{1,6}$ & $\frac{<0,01-59,0}{0,01}$ & $\frac{<0,01-3400}{447}$ & $\frac{1,2-32,0}{16,6}$ & $\frac{<0,01-1900}{329}$ \\
\hline $\mathrm{Cd}$ & & $\frac{0,1-2,8}{1,5}$ & $<0,1$ & $\frac{\leq 0,1-57,0}{6,2}$ & $\frac{0,6-2,3}{1,5}$ & $\frac{1,0-4,6}{2,4}$ \\
\hline $\mathrm{Rb}$ & & $\frac{0,2-3,1}{1,8}$ & $\frac{<0,1-5,4}{0,4}$ & $\frac{0,3-6,2}{1,6}$ & $\frac{0,8-3,9}{2,3}$ & $\frac{11,0-310,0}{60,2}$ \\
\hline $\mathrm{Cr}$ & & $\frac{0,5-4,6}{2,6}$ & $\frac{0,1-0,5}{0,3}$ & $\frac{0,4-19,0}{7,0}$ & $\frac{<0,1-3,0}{1,2}$ & $\frac{1,0-23,0}{10,0}$ \\
\hline Mo & & $<0,1$ & $\frac{0,3-1,3}{0,6}$ & $<0,1$ & $\frac{0,3-8,3}{4,1}$ & $\frac{0,3-28,0}{12,3}$ \\
\hline $\mathrm{U}$ & & $\frac{0,8-4,1}{2,6}$ & $\frac{0,9-3,0}{1,5}$ & $\frac{0,1-5,2}{1,4}$ & $\frac{<0,01-1,6}{0,03}$ & $\frac{0,03-1,9}{1,1}$ \\
\hline
\end{tabular}


Groundwater of long residence time occurs in the mid-Upper Permian sandy sediments, partly in the effusive-sedimentary depositts of the Triassic. The upper distribution limit is at a depth of 100-200 m.

In the upper part of this aquifer (with intensely fractured rocks) water of high TDS (from $0.9-1.5 \mathrm{~g} / \mathrm{L}$ ) and high alkalinity ( $\mathrm{pH}$ from 7.5-9.9) undergoes composition changes, i.e. it becomes sodium bicarbonate. They underlie at a depth of 150-400 m. The microcomponent composition of this water is represented by only two samples (Table 1). The concentrations of most elements are slightly higher than in the overlying waters, but no specific anomaly was observed. Not found in other types of water, it was found only In and Pr in trace amounts of water.

In the lower part of this aquifer (zone of damped fracturing), at a depth from 400-500 $\mathrm{m}$ to $1200 \mathrm{~m}$, and possibly even lower, brackish and even saline (up to $25 \mathrm{~g} / \mathrm{L}$ ) soda water was found. It is located directly within the coal deposits. Such an unusual salinity for soda water increases due to the continuing content increase of $\mathrm{HCO}_{3}{ }^{-}$and $\mathrm{Na}^{+}$. Methane prevails in the composition of water-dissolved gas (70-99\%). The water is enriched mainly with organic substances.

For this water, a wide range of microcomponents in high concentrations was identified. Only for it such elements as $\mathrm{Se}, \mathrm{Co}, \mathrm{As}, \mathrm{Zr}, \mathrm{Hg}$, Cs and Mo were determined. Ba (up to 17 $\mathrm{mg} / \mathrm{L}$ ), B (up to $16 \mathrm{mg} / \mathrm{L}$ ), $\mathrm{Br}$ (up to $8,7 \mathrm{mg} / \mathrm{L}$ ), $\mathrm{Sr}$ (up to $6,2 \mathrm{mg} / \mathrm{L}$ ), $\mathrm{Li}$ (up to $7 \mathrm{mg} / \mathrm{L}$ ), $\mathrm{Pb}$ (up to $1,9 \mathrm{mg} / \mathrm{L}$ ), F (up to $1,5 \mathrm{mg} / \mathrm{L}$ ), Ga (up to $1 \mathrm{mg} / \mathrm{L}$ ), $\mathrm{Zr}$ (up to $0,88 \mathrm{mg} / \mathrm{L}$ ), I (up to 0,5 $\mathrm{mg} / \mathrm{L}$ ), $\mathrm{Rb}$ (up to $0,31 \mathrm{mg} / \mathrm{L}$ ), Mo (up to $28 \mathrm{mg} / \mathrm{L}$ ), Cr (up to $23 \mathrm{mg} / \mathrm{L}$ ), $\mathrm{Zn}$ (up to 0,21 $\mathrm{mg} / \mathrm{L}$ ), V (up to $8 \mathrm{~m} \mu / \mathrm{L}$ ), $\mathrm{Hg}$ (up to $6,28 \mathrm{~m} \mu / \mathrm{L}$ ), Co (up to $5,5 \mathrm{~m} \mu / \mathrm{L}$ ), Cd (up to $4,6 \mathrm{~m} \mu / \mathrm{L}$ ) etc. were in high content compared to other natural waters.

\section{Results and discussion}

General features of the trace element distribution in natural waters are as follows (Fig. 2).

1. In all types of natural waters, the following elements (below the detection limits) were not found: Be, Nd, Sm, Te, Th and Ti. In almost all In, Pr (except in the upper part of long residence time), Ni, Y (except river waters), Se, Co, As, $\mathrm{Zr}, \mathrm{Hg}$, Cs and Mo (except waters with sediments containing coal).

2. The spectrum of the determined microcomponents in all groundwaters is wider and their concentration is usually higher. However, the amount of components exceeding the maximum permissible concentration (MPC) for drinking and household use [4,5] is not so much and all of them are characteristic of only saline soda water of coal deposits: $\mathrm{Ba}$ (100 times), $\mathrm{B}$ and $\mathrm{Pb}$ (10 times), $\mathrm{Li}$ (three times higher than MPC), Cd, J and $\mathrm{Br}$ (2 times), Al and $\mathrm{Hg}$ (at the level of MPC). Reported cases are overwhelmingly natural.

3. The concentrations of elements such as $\mathrm{Ba}, \mathrm{B}, \mathrm{Br}, \mathrm{Sr}, \mathrm{Li}, \mathrm{Mn}, \mathrm{Al}, \mathrm{Pb}, \mathrm{Ga}, \mathrm{Ge}, \mathrm{As}, \mathrm{Sn}$, $\mathrm{Zr}, \mathrm{I}, \mathrm{Rb}, \mathrm{Zr}, \mathrm{Hg}, \mathrm{Co}, \mathrm{Eu}, \mathrm{Nb}$ and $\mathrm{Cu}$ increase with increasing water salinity. Some dependencies are shown in Fig. $2 a-f$. We did not find correlation between salinity and Cs, $\mathrm{La}$ The contents of elements such as $\mathrm{Sc}, \mathrm{V}, \mathrm{Ni}, \mathrm{Bi}, \mathrm{Cd}, \mathrm{Ag}, \mathrm{Sb}$ and $\mathrm{U}$ remain approximately at the same level and do not vary with the values of salinity.

4. The behaviour of organic substances in surface and groundwater is very complex. They are controlled by parameters such as DOC, chemical oxygen absorption (COU), permanganate oxidisability (PO) and fulvic and humic acids (FA and HA). General dependencies of their distribution in different types of water were not identified. Therefore, the study of the relationship of organic substances with microelements did not show any results. Al and $\mathrm{Mn}$, as the only exceptions, revealed a distinct inverse dependence on the DOC index (Fig. $2 i-j$ ). 

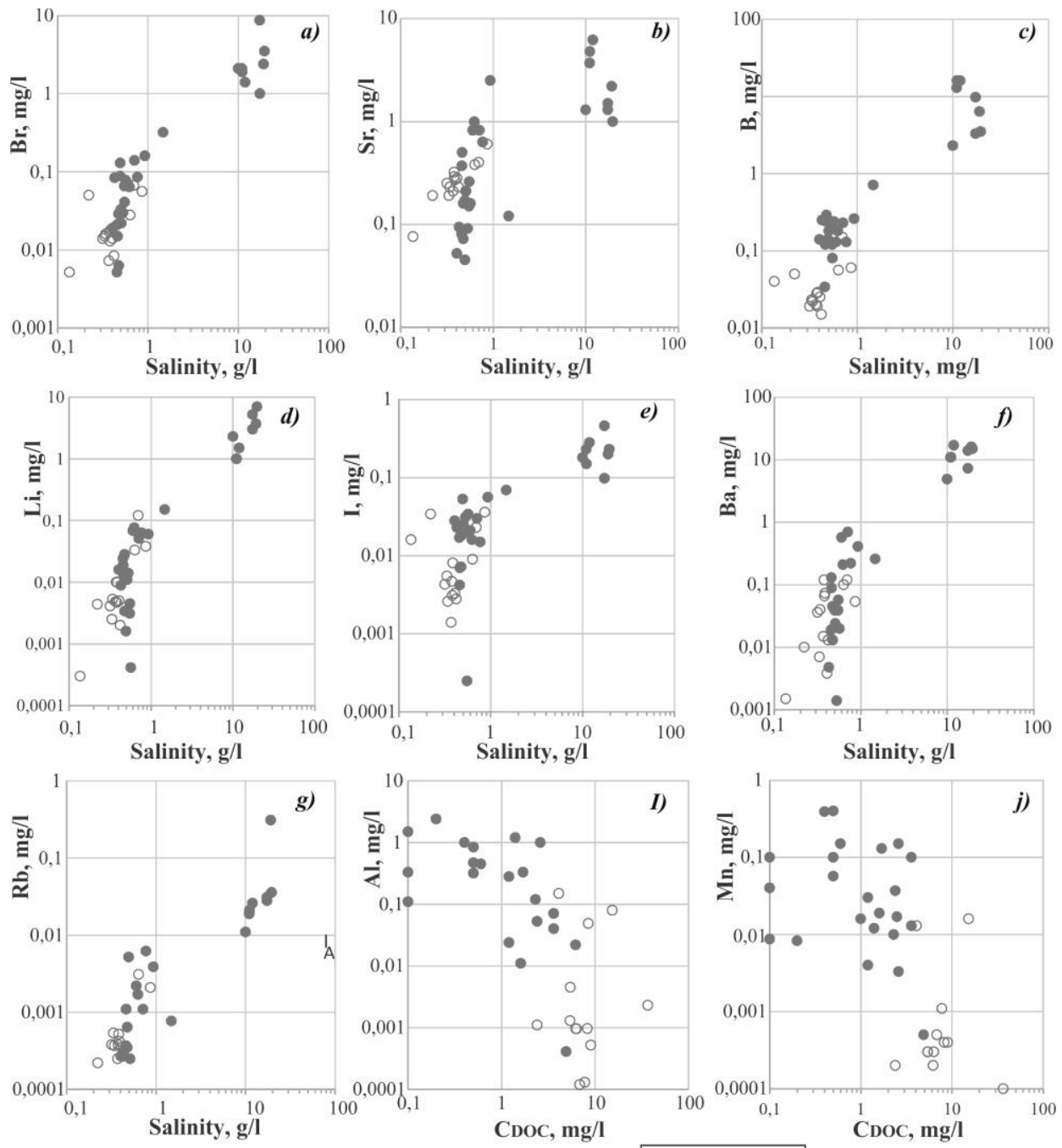

$0-1 \cdot-2$

Fig. 2. Concentration dependences of some microcomponents on salinity and DOC water index: $1-$ surface water; 2 - groundwater.

\section{Conclusion}

Thus, when studying the microcomponent composition of natural water, a sufficiently large range of microelements was analysed; the characteristic features of distribution were described for each type of natural water; the relationship with salinity was determined; and a comparative analysis of their concentration related to the maximum permissible components for drinking water and amenity needs was carried out.

This work represents the preliminary research. In the future, we plan to study the sources of microelements, their migration forms and identify more detailed relationships with water composition.

The authors thank Professor Stepan L. Shvartsev for his contribution. This study was supported by the Russian Science Foundation, project No. 17-17-01158. 


\section{References}

1. S.L. Shvartsev, V.T. Khrukin, E.V. Domrocheva, K.I. Kuzevanov, N.M. Rasskazov, T.S. Popova, O.E. Lepokurova, E.V. Shvachko, Russian Geology and Geophysics, 47 (7), 878-889 (2006)

2. E.V. Domrocheva, O.E. Lepokurova, D.A. Sizikov, Bulletin of the Tomsk Polytechnic University [in Russian], 325 (1), 94-101 (2014)

3. S.L. Shvartsev, Hydrogeochemistry of hypergenesis zone [in Russian], 367 (1998)

4. Sanitary - epidemiological rules and norms 2.1.4.1074-01. [in Russian], 103 (2002)

5. Health standards 2.1.5.1315-03. [in Russian], 93 (2003) 